\title{
WNT pathway inhibitor pyrvinium pamoate inhibits the self-renewal and metastasis of breast cancer stem cells
}

\author{
LIANG XU ${ }^{1,3^{*}}$, LE ZHANG ${ }^{1,3^{*}}, \mathrm{CHUN} \mathrm{HU}^{1}$, SHUJING LIANG $^{1}$, XIAOCHUN FEI ${ }^{2}$, \\ NINGNING YAN ${ }^{1,3}$, YANYUN ZHANG ${ }^{4}$ and FENGCHUN ZHANG ${ }^{1,3}$ \\ Departments of ${ }^{1}$ Oncology and ${ }^{2}$ Pathology, Ruijin Hospital, Shanghai Jiaotong University \\ School of Medicine, Shanghai 200025; ${ }^{3}$ Department of Oncology, Suzhou Kowloon Hospital, \\ Shanghai Jiaotong University School of Medicine, Suzhou, Jiangsu 215021; \\ ${ }^{4}$ Institute of Health Sciences, Shanghai Institutes for Biological Sciences, \\ Chinese Academy of Sciences \& SJTUSM, Shanghai 200031, P.R. China
}

Received November 18,2015; Accepted December 17, 2015

DOI: $10.3892 /$ ijo.2016.3337

\begin{abstract}
Acquisition of chemoresistance and metastatic phenotype are the major causes of breast cancer treatment failure and cancer-related mortality. Recently, a plethora of experimental and clinical studies points toward a central role of cancer stem cells (CSCs) in the chemoresistance and metastasis. In the present study, we demonstrated that pyrvinium pamoate (PP), an anthelmintic drug, inhibited proliferation of different subtypes of breast cancer cells (luminal: MCF-7, claudin-low: MDA-MB-231, basal-like: MDA-MB-468 and Her-2 enriched: SkBr-3) as a novel WNT pathway inhibitor. Additionally, PP was also shown to inhibit self-renewal of breast cancer stem cells (BCSCs) and decrease both $\mathrm{CD} 44^{+} \mathrm{CD} 24^{-/ \text {low }}$ and $\mathrm{ALDH}$-positive BCSCs content in a panel of breast cancer cell lines. Besides, the metastatic potential and expression of EMT markers (such as N-cadherin, vimentin, Snail) were also found suppressed by PP. By using a xenograft model, we next tested the efficacy of PP on tumorigenicity of MDA-MB-231, one of the most aggressive breast cancer cell lines, and we observed PP significantly delayed tumor growth in vivo. Moreover, in-depth analysis revealed that PP caused inhibition of WNT pathway activity and stemness regulator expression including NANOG, SOX2 and OCT4, which were inherently upregulated in the BCSCs as compared with the bulk of cells within the tumor. Collectively, our findings provide direct evidence for PP
\end{abstract}

Correspondence to: Professor Fengchun Zhang, Department of Oncology, Ruijin Hospital, Shanghai Jiaotong University School of Medicine, 297 Second Ruijin Road, Shanghai 200025, P.R. China E-mail: fczhang2005@163.com

${ }^{*}$ Contributed equally

Key words: pyrvinium pamoate, WNT pathway, breast cancer stem cells, heterogeneity, mammosphere serving as a promising high-yield agent targeting BCSCs and cancer heterogeneity. Therefore, strategies combining PP with standard chemotherapy drugs which fail to eliminate the BCSCs hold promise to overcome BCSCs associated treatment resistance and achieve a better therapeutic outcome.

\section{Introduction}

Currently, a rapidly growing body of research demonstrates that breast cancer arises from a small population of cancer cells termed as 'cancer stem cells' (CSCs) or 'tumor-initiating cells' (TICs) (1). CSCs are endowed with self-renewing and unlimited proliferation potential $(2,3)$, and it is conceivable that CSCs also share with normal stem cells several properties such as the relative quiescence, resistance to drugs or toxins through expression of drug transporters, a better ability to repair DNA and resistance to apoptosis and hypoxia, which is critical to enable them to survive for extended periods (4-7). As a result, typical chemo-radiotherapies could only eliminate the bulk of the tumor, but CSCs would survive and develop into a new tumor over time. Therefore, the discovery and development of specific therapies that target CSCs has the potential to revolutionize the treatment of malignant tumors $(4,8)$.

Signaling pathways that support stem cell self-renewal appear to be promising cancer treatment candidates for personalized therapy. Several developmental pathways, such as Notch, Sonic Hedgehog (Shh), WNT are involved in regulation of self-renewal of normal stem cells. However, dysregulation of these pathways also contributes to the maintenance of CSCs (9-13). In fact, numerous 'stemness' related genes are also oncogenes, and many genes that inhibit self-renewal are also tumor suppressor genes. These observations suggest the CSCs originate from normal stem cells with somatic mutants accumulation during aging, and cancer is essentially a disease of 'stemness' gone awry (14). Compounds that converge on these cell-intrinsic pathways may overcome the dynamic nature of CSCs and thereby prevent the evolution of CSC clones that drive tumor initiation, maintenance, and relapse $(15,16)$. 
Notably,some researchershavereported pyrvinium pamoate (PP), a well-known anthelmintic drug, exhibited a potent antitumor activity against several cancers including myeloma (17), glioblastoma (15), colon cancer (18) and lung cancer (19) as a selective WNT pathway inhibitor. Although the WNT signaling pathway is important for cell proliferation and differentiation, cell movement and polarity, and maintenance of self-renewal in CSCs (20), whether pharmacologic blocking of the WNT signaling pathway with PP in breast cancer could provide therapeutic possibility by inhibiting breast cancer stem cells (BCSCs) remains to be elucidated.

Importantly, breast tumors are comprised of phenotypically diverse populations of breast cancer cells (21). In the past decade, the genomic studies have established at least five different breast cancer subtypes with difference in incidence, drug response and survival: the luminal A and $\mathrm{B}$, Her-2 overexpressing (OE), basal-like, and normal breast-like tumors (22). Moreover, BCSCs are also heterogeneous and the existence of various BCSC subpopulations which would lead to a rapid relapse after primary treatments might pose a problem for cancer therapy $(23,24)$. Virtually, therapeutic failure is in part due to the heterogeneity imparting phenotypic diversity within the CSCs $(25,26)$. Each cancer subtype contains distinct CSC subpopulations expressing different CSC markers, and the molecular difference of the CSCs also imply different outcome in response to the current treatment $(24,27)$.

In the present study, PP was tested for its ability to suppress the self-renewal and mammosphere-formation ability of BCSCs derived from distinct molecular subgroups (luminal: MCF7, Her-2 OE: SK-BR3, claudin-low: MDA-MB-231, basallike: MDA-MB-468). Moreover, we also evaluated the efficacy of PP suppressing breast cancer motility and EMT process in vitro. Additionally, the ability of PP to suppress BCSC selfrenewal in vivo and the potential mechanisms involved were also examined.

\section{Materials and methods}

Antibodies and reagents. Rabbit monoclonal anti-NANOG, anti-SOX2, anti-GAPDH, anti-E-cadherin, anti-Ki67 and anti-vimentin were from Cell Signaling Technology. Rabbit polyclonal anti-OCT4, monoclonal anti-N-cadherin were from Abcam. Goat anti-rabbit IgG-HRP was from Santa Cruz Biotechnology. Antibodies to FITC-conjugated CD44, and PE-conjugated CD24 were from Miltenyi Biotec. Pyrvinium pamoate was purchased from Sigma-Aldrich, and it was dissolved in DMSO at a concentration of $1 \mu \mathrm{mol} / 1$ and was stocked in aliquots at $-20^{\circ} \mathrm{C}$.

Cell culture. Human breast cancer cell lines MCF-7, MDAMB-231, MDA-MB-468 and SkBr-3 were obtained from American Type Culture Collection (www.atcc.org). These cells above were routinely cultured in their recommended media containing 10\% fetal bovine serum (FBS) (Gibco), $100 \mathrm{U} / \mathrm{ml}$ penicillin and $100 \mu \mathrm{g} / \mathrm{ml}$ streptomycin (Invitrogen) at $37^{\circ} \mathrm{C}$ in a humidified chamber with $5 \% \mathrm{CO}_{2}$.

Mammosphere formation assay. For mammosphere assay, a single cell suspension was prepared at a density of $10^{4} / \mathrm{ml}$ in culture medium and were plated in the ultra-low attachment 6-well plates (Corning). The mammosphere culture medium was serum-free DMEM/F-12 (1:1) (Hyclone) supplemented with $20 \mathrm{ng} / \mathrm{ml}$ human basic fibroblast growth factor (Gibco), $20 \mathrm{ng} / \mathrm{ml}$ human epidermal growth factor (Gibco), 1xB27 (Invitrogen), and $5 \mu \mathrm{g} / \mathrm{ml}$ insulin (Sigma-Aldrich). Culture medium was replenished every 3 days and images were taken at day 7 .

Colony formation assay. Cells were resuspended in culture medium containing 10\% FBS with or without PP and seeded at a density of $1 \times 10^{3} / \mathrm{dish}$ into a $6-\mathrm{cm}$ dish. Cells were kept for two weeks and monitored for colony formation. To evaluate the colony formation, cells were fixed and then stained with crystal violet (Beyotime) for $15 \mathrm{~min}$ after the culture period. The clones consisting of a minimum of 50 cells were counted.

In vitro proliferation assay. Cells $\left(1 \times 10^{4}\right)$ were suspended in $200 \mu 1$ culture medium and then seeded into 96-well plates (Corning) in quintuplicate overnight. Cells were treated with indicated concentrations of $\mathrm{PP}(0-8,000 \mu \mathrm{M})$. After incubating for 3 days, Cell Counting kit-8 (CCK8) assay was conducted according to the manufacturer's protocol (28). CCK8 (10 $\mu \mathrm{l})$ (Dojindo) was added into each well and incubated at $37^{\circ} \mathrm{C}$ for $1 \mathrm{~h}$. The absorbance was measured using a microplate reader at $450 \mathrm{~nm}$ (Tecan). The measured optical density (OD) values were directly proportional to the number of viable cells. Then, dose-response curves were fitted to the data and the halfmaximal inhibitory concentrations $\left(\mathrm{IC}_{50} \mathrm{~s}\right)$ were calculated using SPSS software package (v19.0; IBM Corp., Armonk, NY, USA). All experiments were repeated at least three times. The cell proliferation rate was calculated as follows: Cell proliferation rate $(\%)=$ Experimental group OD value/Control group OD value x $100 \%$ (1).

$C D 44^{+} / C D 24^{-l l o w}$ cell population. Cells were resuspended as single cell in PBS with 5\% FBS and incubated with FITC mouse anti-human CD44 (\#130-095-195, 1:100, Miltenyi Biotec) and PE mouse anti-human CD24 (\#130-095-953, 1:100, Miltenyi Biotec) for $15 \mathrm{~min}$ at $4^{\circ} \mathrm{C}$ in the dark. Analysis was performed using a FACS Aria II cell sorter (BD Biosciences).

ALDEFLUOR assay. The ALDEFLUOR kit (Stem Cell Technologies) was used to detect the cell populations with high aldehyde dehydrogenase (ALDH) enzyme activity according to the manufacturer's instructions. After incubating with or without PP for $72 \mathrm{~h}$, cells were resuspended at a density of $10^{6} / \mathrm{ml}$ in ALDH assay buffer containing the ALDH substrate BAAA $(1 \mathrm{mM})$ and incubated for $30 \mathrm{~min}$ at $37^{\circ} \mathrm{C}$. As a negative control, a sample of cells was incubated with $50 \mathrm{mM}$ of diethylaminobenzaldehyde (DEAB), a specific ALDH inhibitor. A FACS Aria II cell sorter was used to analyse the ALDH-positive cell population.

Migration/invasion assay. Migration assays were performed in 24-well Falcon tissue culture plate with non-coated membrane transwells (pore size, $8.0 \mu \mathrm{m}$, Merck Millipore). PP-pretreated (1x105; MDA-MB-231: $500 \mathrm{nM}, 72 \mathrm{~h}$; MDA-MB-468: $100 \mathrm{nM}$, $72 \mathrm{~h}$ ) or untreated breast cancer cells were seeded on the top chamber and starved overnight, and then incubated for $24 \mathrm{~h}$ 
using 10\% FBS DMEM as chemoattractant. Then the cells on the top of the insert were removed with a cotton swab. The invasion assay was performed as described for migration assay by using $1.5 \times 10^{5}$ cells and Matrigel-coated membrane. Migrated cells on the lower surface were fixed with ice-cold $4 \%$ paraformaldehyde, stained with $0.1 \%$ crystal violet and then photographed and counted.

In vivo xenograft assay. NOD/SCID mice were housed under aseptic conditions in individually ventilated cages. For xenografting, $5 \times 10^{6}$ PP-pretreated or untreated breast cancer cells (MDA-MB-231) were resuspended in a 1:1 mixture of culture medium and Matrigel (BD Biosciences) and then transplanted into the fourth pair of mammary fat pads of mice (4-6-week-old) as previously described (29). After injection, tumor size was measured by calipers each day and tumor growth was plotted. Upon reaching the endpoint, mice were sacrificed and tumors were harvested. All the tumors were formalin-fixed, and paraffin-embedded for hematoxylin and eosin (H\&E) and immunohistochemical (IHC) staining. All staining was performed with standard protocols and analyzed by a pathologist (Xiaochun Fei) who specializes in breast cancer. The rabbit anti-Ki67 monoclonal antibody (\#9027S, 1:200) used for IHC was purchased from Cell Signaling Technology. All experiments were performed in accordance with guidelines of Shanghai Jiaotong University (SJTU) animal care and use committee.

qPCR assay. Total RNA was extracted using TRIzol reagent (Invitrogen) according the manufacturer's instructions. RNA integrity was verified using the Experion automated electrophoresis station (Bio-Rad), and the RNA concentration was measured at $260 \mathrm{~nm}$. The qPCR assays were conducted with the aid of a FastStart Universal SYBR Green Master kit (Roche) and an ABI PRISM 7900HT sequence detection system (Applied Biosystems). The cycler protocol was $5 \mathrm{~min}$ at $95^{\circ} \mathrm{C}, 40$ cycles with $15 \mathrm{sec}$ at $95^{\circ} \mathrm{C}, 60 \mathrm{sec}$ at $60^{\circ} \mathrm{C}$, and $5 \mathrm{~min}$ at $72^{\circ} \mathrm{C}$. Gene of interest expression was normalized to the reference genes GAPDH, and fold expression was calculated with the $2^{-\Delta \Delta C t}$ method (30). The primers used in the present study are listed in Table I.

Western blotting. Cultured cells were washed with ice-cold PBS three times, harvested, and lysed in RIPA buffer (Pierce) for immunoblot analysis. In brief, the supernatants containing $10 \mu \mathrm{g}$ total protein were electrophoresed on $10-12 \%$ gradient sodium dodecyl sulfate-polyacrylamide gels (SDS-PAGE) and then transferred to polyvinylidene fluoride membranes (Bio-Rad). Membranes were blocked in 5\% (w/v) skim milk for $1 \mathrm{~h}$ at room temperature and then incubated at $4^{\circ} \mathrm{C}$ overnight with the primary antibodies. Membranes were then incubated with horseradish peroxidase-conjugated secondary antibodies (Santa Cruz Biotechnology) for $1 \mathrm{~h}$ at room temperature and detected using ECL Prime Western Blotting Detection Reagent (GE Healthcare). Images were obtained using a LAS-3000 Imager (Fuji film). The primary antibodies used were NANOG (\#4903S, 1:1,000, Cell Signaling Technology), SOX2 (\#3579S, 1:1,000, Cell Signaling Technology), GAPDH (\#5174, 1:2,000, Cell Signaling Technology), OCT4 (\#ab109183, 1:1,000, Abcam), E-cadherin (\#3195, 1:1,000, Cell Signaling
Technology), N-cadherin (\#ab18203, 1:1,000, Abcam) and vimentin (\#5741, 1:1,000, Cell Signaling Technology).

Statistical analysis. All graphs and statistical analyses were made using Prism 5 statistical software (GraphPad Software, Inc.), unless otherwise stated. Student's t-test was employed for two-group comparisons. The results are expressed as mean \pm standard deviation (SD). All experimental data were obtained from at least three experimental repeats and P-values $<0.05$ were considered statistically significant. Bar graphs show mean values with $95 \%$ confidence intervals.

\section{Results}

PP inhibits proliferation of different breast cancer cells. In order to evaluate the effects of PP on proliferation in breast cancer cells, cell viabilities were examined after exposing four breast cancer cell lines to varying concentrations of PP for 3 days. We found PP efficiently decreased the viabilities on MCF-7 (luminal), MDA-MB-231 (claudin-low), MDA-MB-468 (basal-like) and SkBr3 (HER2-OE) cells in a dose-dependent manner (Fig. 1A). The half-maximal inhibitory concentrations $\left(\mathrm{IC}_{50} \mathrm{~s}\right)$ of PP were used at a nanomole concentration and they vary considerably among diverse subtypes. Of interest, MDA-MB-231, a claudin-low breast cancer cell line, was relatively insensitive to the $\mathrm{PP}$ treatment with a $\mathrm{IC}_{50}$ value of $1170 \pm 105.0 \mathrm{nM}$ (Fig. 1B).

$P P$ inhibits self-renewal capacity of BCSCs in vitro. As the cardinal property of stemness, self-renewal is defined by the ability of a cell, at each cell division, to generate an identical copy of itself and a cell of the same or different phenotype (31). Moreover, because the mammosphere culture mirrors in vitro tumorigenic capacity and it can also retrospectively identify CSCs that develop from single stem cell-like clones $(32,33)$, mammosphere formation assay was utilized in our study. As shown in Fig. 2A, mammospheres were successfully generated from MCF-7, MDA-MB-468, SkBr3, and MDA-MB-231 cells. Furthermore, we evaluated whether PP could exert influence on self-renewal capacity of BCSCs. In the mammosphere formation assay, PP was shown to significantly reduce both the number and size of mammospheres in vitro (Fig. 2B). As a consequence of these findings, we next tested its effect on colony formation. As expected, our findings also directly illustrated that PP was effective against colony formation across all four cell lines tested (Fig. 2C and D). Taken together, our results demonstrated that PP significantly inhibits self-renewal and proliferation of BCSCs.

PP decreases different BCSC subpopulations. Both $\mathrm{CD} 44^{+} /$ $\mathrm{CD} 24^{- \text {llow }}$ and ALDH-positive have been widely used as specific markers to identify the BCSCs from breast cancer tissues, and the putative BCSCs are capable of self-renewal and generating tumors resembling breast cancer (34). To this end, we further evaluated whether PP was able to eliminate the BCSCs with $\mathrm{CD} 44^{+} \mathrm{CD} 24^{-/ \text {low }}$ or ALDH-positive phenotype directly. Results of the flow cytometric assay depicted that after 3-day treatment, PP markedly reduced the $\mathrm{CD} 44^{+} \mathrm{CD} 24^{-/ \text {low }}$ population in different breast cancer cell lines (MCF-7, MDA-MB-231: Fig. 3A and B; MDA-MB-468: data not shown), compared with 
Table I. Primer sequences.

\begin{tabular}{|c|c|c|c|}
\hline \multirow{2}{*}{$\begin{array}{l}\text { Gene } \\
\text { GAPDH }\end{array}$} & \multicolumn{2}{|r|}{ Primers } & \multirow{2}{*}{$\frac{\text { Sapien }}{\text { Homo }}$} \\
\hline & Forward: & 5' GGA GCG AGA TCC CTC CAA AAT 3' & \\
\hline & Reverse: & 5' GGC TGT TGT CAT ACT TCT CAT GG 3' & Hото \\
\hline \multirow[t]{2}{*}{$\mathrm{N}$-cadherin } & Forward: & 5' AGC CAA CCT TAA CTG AGG AGT 3' & Homo \\
\hline & Reverse: & 5' GGC AAG TTG ATT GGA GGG ATG 3' & \\
\hline \multirow[t]{2}{*}{ E-cadherin } & Forward: & 5' ATT TTT CCC TCG ACA CCC GAT 3' & Homo \\
\hline & Reverse: & $5^{\prime}$ TCC CAG GCG TAG ACC AAG A 3' & \\
\hline \multirow[t]{2}{*}{ Slug } & Forward: & 5' TGT GAC AAG GAA TAT GTG AGC C 3' & Homo \\
\hline & Reverse: & 5' TGA GCC CTC AGA TTT GAC CTG 3' & \\
\hline \multirow[t]{2}{*}{ Snail } & Forward: & 5' ACT GCA ACA AGG AAT ACC TCA G 3' & Homo \\
\hline & Reverse: & 5' GCA CTG GTA CTT CTT GAC ATC TG 3' & \\
\hline \multirow[t]{2}{*}{ Twist1 } & Forward: & 5' GTC CGC AGT CTT ACG AGG AG 3' & Homo \\
\hline & Reverse: & 5' GCT TGA GGG TCT GAA TCT TGC T 3' & \\
\hline \multirow[t]{2}{*}{ ZEB1 } & Forward: & 5' TTA CAC CTT TGC ATA CAG AAC CC 3' & Homo \\
\hline & Reverse: & 5' TTT ACG ATT ACA CCC AGA CTG C 3' & \\
\hline \multirow[t]{2}{*}{ ZEB2 } & Forward: & 5' GCG ATG GTC ATG CAG TCA G 3' & Homo \\
\hline & Reverse: & 5' CAG GTG GCA GGT CAT TTT CTT 3' & \\
\hline \multirow{2}{*}{ NANOG } & Forward: & 5' TTT GTG GGC CTG AAG AAA ACT 3' & Homo \\
\hline & Reverse: & 5' AGG GCT GTC CTG AAT AAG CAG 3' & \\
\hline \multirow[t]{2}{*}{ OCT4 } & Forward: & 5' CTT GAA TCC CGA ATG GAA AGG G 3' & Homo \\
\hline & Reverse: & 5' GTG TAT ATC CCA GGG TGA TCC TC 3' & \\
\hline \multirow{2}{*}{ SOX2 } & Forward: & 5' TAC AGC ATG TCC TAC TCG CAG 3' & Homo \\
\hline & Reverse: & 5' GAG GAA GAG GTA ACC ACA GGG 3' & \\
\hline \multirow[t]{2}{*}{ KLF4 } & Forward: & 5' CAG CTT CAC CTA TCC GAT CCG 3' & Homo \\
\hline & Reverse: & 5' GAC TCC CTG CCA TAG AGG AGG 3' & \\
\hline \multirow{2}{*}{ ABCG2 } & Forward: & 5' ACG AAC GGA TTA ACA GGG TCA 3' & Homo \\
\hline & Reverse: & 5' CTC CAG ACA CAC CAC GGA T 3' & \\
\hline \multirow[t]{2}{*}{ ALDH1 } & Forward: & 5' GCA CGC CAG ACT TAC CTG TC 3' & Homo \\
\hline & Reverse: & 5' ССТ ССТ CAG TTG CAG GAT TAA AG 3' & \\
\hline \multirow[t]{2}{*}{ CD44 } & Forward: & 5' CTG CCG CTT TGC AGG TGT A 3' & Homo \\
\hline & Reverse: & 5' CAT TGT GGG CAA GGT GCT ATT 3' & \\
\hline \multirow[t]{2}{*}{ WNT1 } & Forward: & 5' CGA TGG TGG GGT ATT GTG AAC 3' & Homo \\
\hline & Reverse: & 5' CCG GAT TTT GGC GTA TCA GAC 3' & \\
\hline \multirow[t]{2}{*}{ WNT7B } & Forward: & 5' GAA GCA GGG CTA CTA CAA CCA 3' & Homo \\
\hline & Reverse: & 5' CGG CCT CAT TGT TAT GCA GGT 3' & \\
\hline \multirow[t]{2}{*}{ MYC } & Forward: & 5' CAC CTT GTA GCA CGT CCT G 3' & Homo \\
\hline & Reverse: & 5' GAC TCC CCA AGA TGT GGT GG 3' & \\
\hline \multirow[t]{2}{*}{ LRP5 } & Forward: & 5' TGG CCC GAA ACC TCT ACT G 3' & Homo \\
\hline & Reverse: & 5' GCA CAC TCG ATT TTA GGG TTC T 3' & \\
\hline \multirow[t]{2}{*}{ FZD1 } & Forward: & 5' AGC CAT CCA GTT GCA CGA G 3' & Homo \\
\hline & Reverse: & 5' GAG TCG GGC CAC TTG AAG TT 3' & \\
\hline FZD10 & Forward: & 5' GGC GGT GAA GAC CAT CCT G 3' & Homo \\
\hline & Reverse: & 5' GGC GGT GAA GAC CAT CCT G 3' & \\
\hline CTNNB1 & Forward: & 5' CAT CTA CAC AGT TTG ATG CTG CT 3' & Homo \\
\hline & Reverse: & 5' GCA GTT TTG TCA GTT CAG GGA 3' & \\
\hline Gli1 & Forward: & 5' GTG CAA GTC AAG CCA GAA CA 3' & Homo \\
\hline & Reverse: & 5' ATA GGG GCC TGA CTG GAG AT 3' & \\
\hline Gli2 & Forward: & 5' CAT GGA GCA CTA CCT CCG TTC 3' & Homo \\
\hline & Reverse: & 5' CGA GGG TCA TCT GGT GGT AAT 3' & \\
\hline HES1 & Forward: & 5' TCA ACA CGA CAC CGG ATA AAC $3^{\prime}$ & Homo \\
\hline & Reverse: & 5' GCC GCG AGC TAT CTT TCT TCA 3' & \\
\hline
\end{tabular}


A
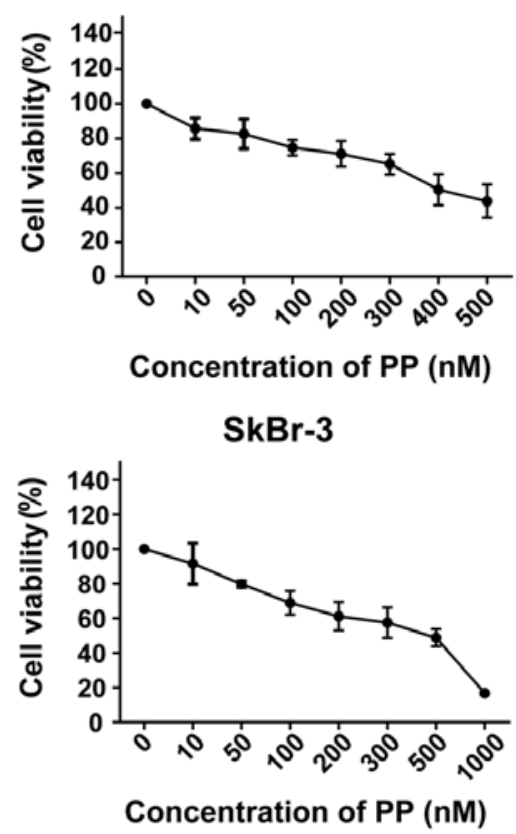

MDA-MB-231

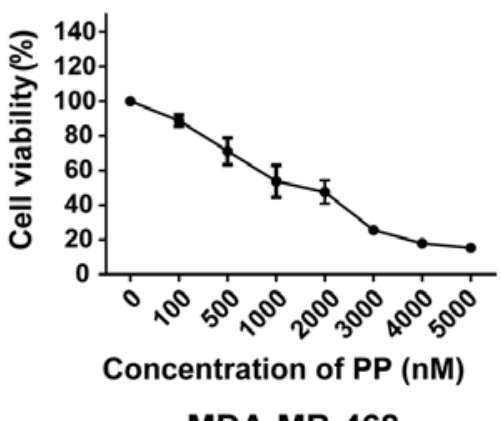

MDA-MB-468

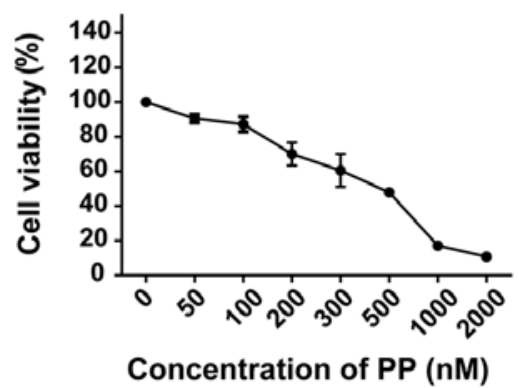

B

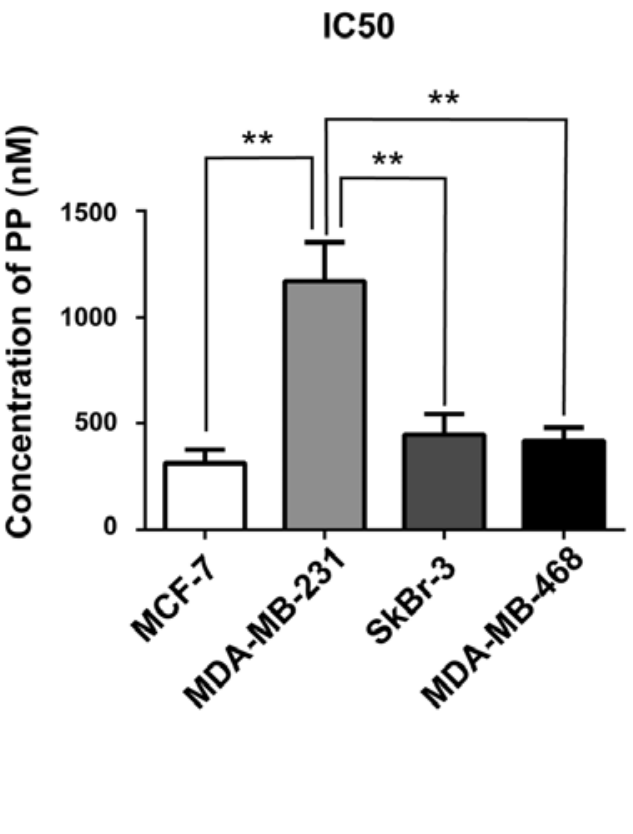

Figure 1. PP inhibits proliferation of breast cancer cells. (A) Different breast cancer cells growing in the log phase were treated with increasing concentrations of PP for $96 \mathrm{~h}$. The anti-proliferation effect of PP was evaluated by Cell Counting kit-8 (CCK8) assay. (B) IC ${ }_{50} \mathrm{~s}$ of the four breast cancer cell lines. ${ }^{*} \mathrm{P}<0.05$ and ${ }^{* *} \mathrm{P}<0.01$. All the experiments were repeated three times and error bars represent standard deviations (SD). PP, pyrvinium pamoate; $\mathrm{IC}_{50}$, the half-maximal inhibitory concentration.

the control $(\mathrm{P}<0.05)$. Similarly, a decline of ALDH-positive cell population was also observed in PP-treated cells (MCF-7, MDA-MB-231: Fig. 3C and D; SkBr-3, MDA-MB-468: data not shown). Actually, recent studies have identified $\mathrm{CD} 44^{+} \mathrm{CD} 24^{-/ \text {low }}$ and ALDH-positive phenotypes probably refer to different BCSC populations $(2,35)$. Our results therefore indicated PP can suppress BCSC population with a distinct phenotype.

$P P$ reduces tumorigenicity of $B C S C$ s in vivo. In our xenograft model, $5 \times 10^{6}$ PP-pretreated or untreated breast cancer cells (MDA-MB-231) were injected into the cleared mammary fat pads of NOD/SCID mice. All the tumor tissues were confirmed with hematoxylin and eosin (H\&E) staining. We observed that PP-pretreatment strongly delayed tumor size and tumor weight (Fig. 4A and B). Furthermore, the tumor growth curves demonstrated that the tumor volume of PP-pretreated group was markedly decreased, compared with control group $(\mathrm{P}<0.05)$ (Fig. 4C). Immunohistochemical staining also found significantly lower Ki-67 expression in the PP-pretreated group (Fig. 4D), supporting our hypothesis of PP effectively targeting self-renewal and proliferation of BCSCs in vitro and in vivo.

PP inhibits breast cancer cell invasiveness and EMT process. To extend our analysis of the role of PP in cell motility, we applied Transwell assays to evaluate the breast cancer cell migratory and invasive potential of two of the most aggressive breast cancer cell lines (MDA-MB-231, MDA-MB-468) in the absence or presence of PP. As shown in Fig. 5A-D, PP significantly inhibited cell motility and reduced the number of cells that migrated through the membrane. Because EMT has a major role in cancer metastasis and maintenance of
BCSCs, the expression levels of epithelial and mesenchymal markers were also examined. We found PP greatly increased the expression of the epithelial marker E-cadherin. For mesenchymal markers $\mathrm{N}$-cadherin and vimentin, however, $\mathrm{PP}$ treatment effectively decreased their expression both at translational and transcriptional levels (Fig. 5E and F). Moreover, a high mRNA expression of well-known transcriptional repressors of E-cadherin (such as Snail, ZEB1 and Twist1) were also observed (Fig. 5E). Collectively, these results indicated PP attenuates the migratory and invasive properties of cancer cells and EMT process.

PP effectively attenuates WNT signaling and downregulates stemness regulators. We next investigated the mechanisms underlying the inhibitory effects of PP on BCSCs. Recently, WNT signaling pathway was reported to play a pivotal role in sustaining self-renewal potential and chemoresistance in CSCs (20). Aberrant activation of CTNNB1, MYC, and LRP5 is known as key process of the WNT signaling pathway. As shown in Fig. 6A, we observed that PP significantly decreased average expression levels of FZD1, FZD10, WNT1, WNT7B, CTNNB1, MYC, and LRP5 at transcriptional level compared with control. Additionally, a prior study has reported that pyrvinium is a potent inhibitor of Sonic Hedgehog (Shh) signaling, which acts by reducing the stability of the Gli family of transcription factors (36). Interestingly, a decrease of Gli1 and Gli2 was also confirmed with Q-PCR assay in the present study, whereas the mRNA level of HES1, the target gene of Notch pathway, remained unaltered (Fig. 6A).

Because several self-renewal genes including NANOG, OCT4 and SOX2 are key regulators of stemness in CSCs (37), we further explored whether PP downregulates these stemness 
A

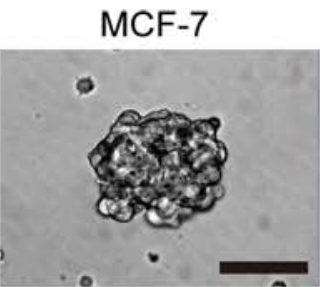

MDA-MB-231

SkBr-3

MDA-MB-468

B

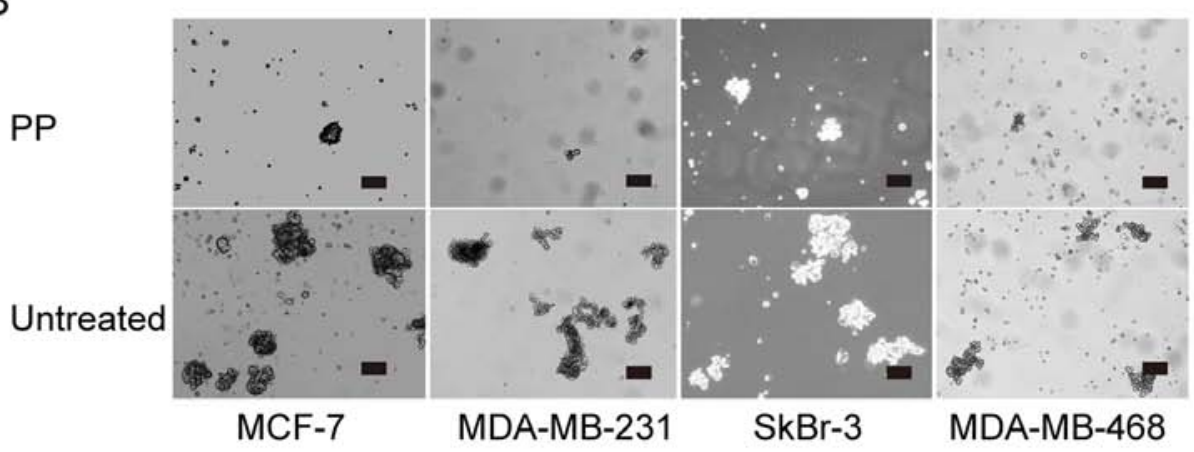

C
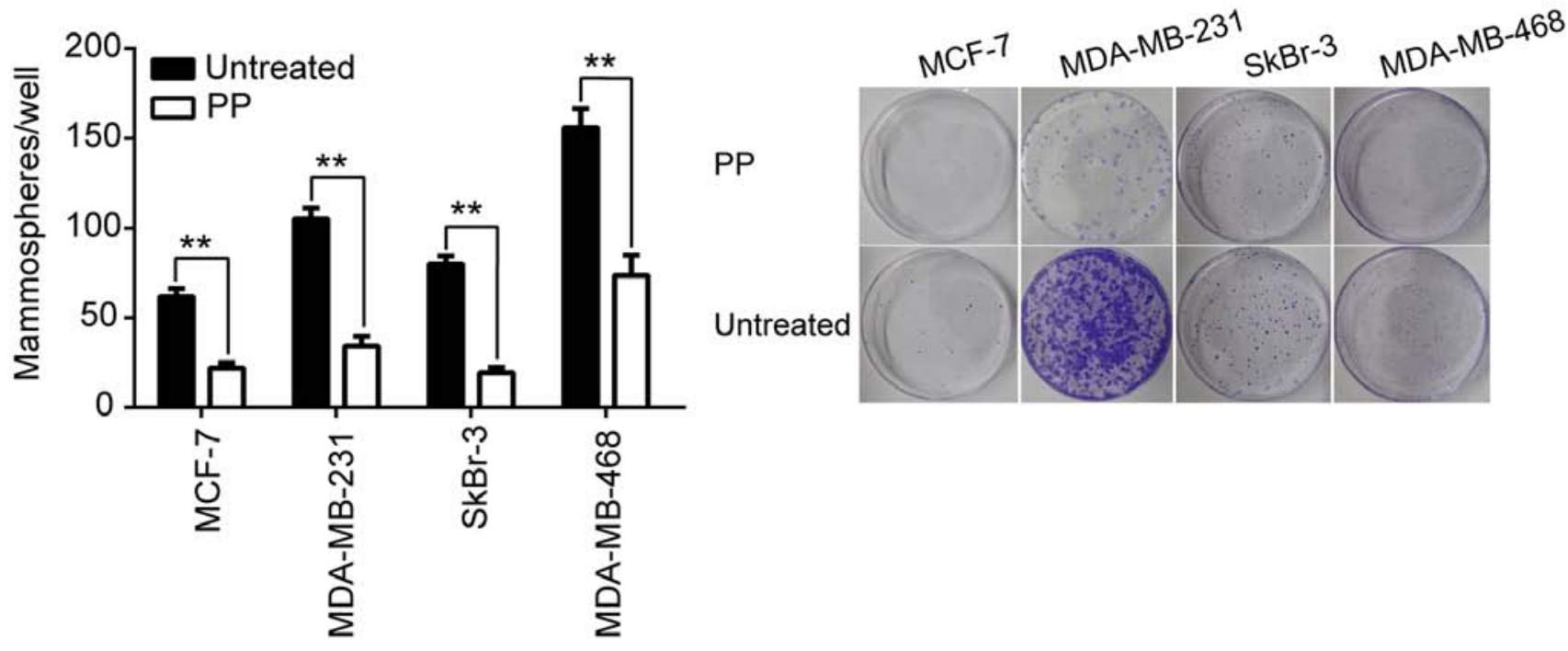

E
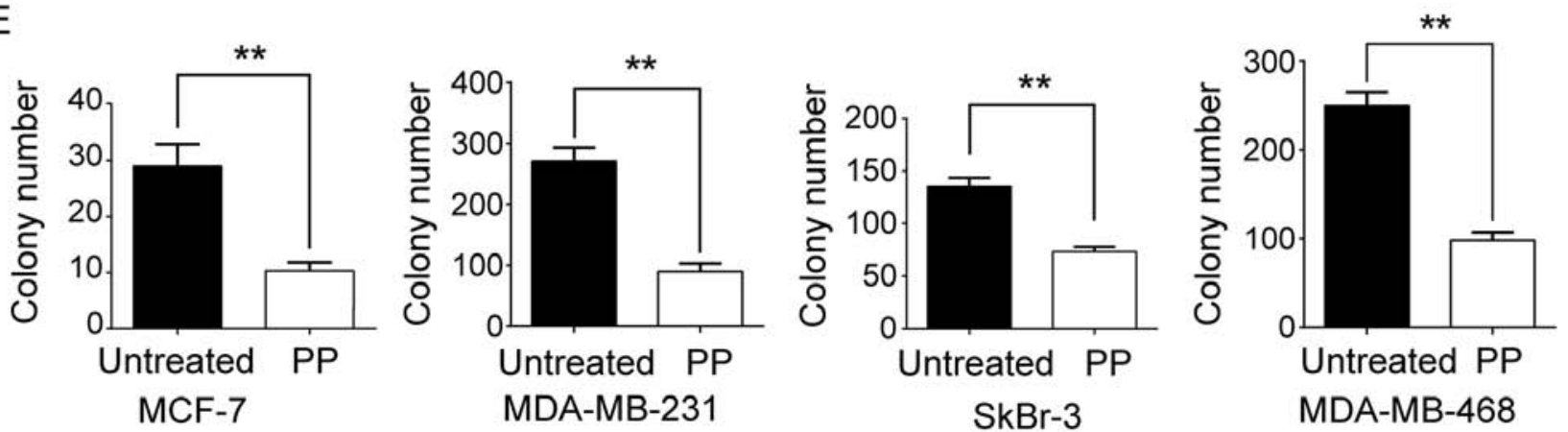

Figure 2. PP effectively inhibits self-renewal of BCSCs. (A) Morphology of mammospheres derived from different breast cancer cell lines. Cells were cultured in non-adherent culture conditions for 7 days, and images were captured by a microscope. (B) Representative images of mammosphere formation assay of four breast cancer cell lines in the absence or presence of PP. The dose of PP used for MCF-7, SkBr-3, MDA-MB-231, and MDA-MB-468 was 100, 200,500 and $200 \mathrm{nM}$, respectively. (C) Cell counting results of mammosphere formation assay. (D) Colony formation assay of different breast cancer cell lines in the absence or presence of PP. The dose of PP used for MCF-7, MDA-MB-231, SkBr-3 and MDA-MB-468 was 100, 200, 100 and $100 \mathrm{nM}$, respectively. (E) Cell counting results of colony formation assay. Data are reported as means $\pm \mathrm{SD}$ of three independent experiments. ${ }^{*} \mathrm{P}<0.05,{ }^{* *} \mathrm{P}<0.01$ and ${ }^{* * * *} \mathrm{P}<0.001$. Scale bar, $100 \mu \mathrm{m}$. PP, pyrvinium pamoate; BCSC, breast cancer stem cell.

genes in vitro. Our data revealed significantly lower expression of these stem cell markers in the PP-treated breast cancer cells in comparison with untreated cells both at mRNA and protein levels (Fig. 6B and C). Moreover, PP also efficiently down- 
A

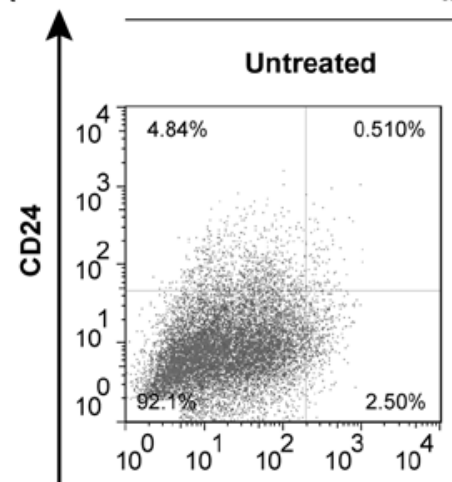

MCF-7

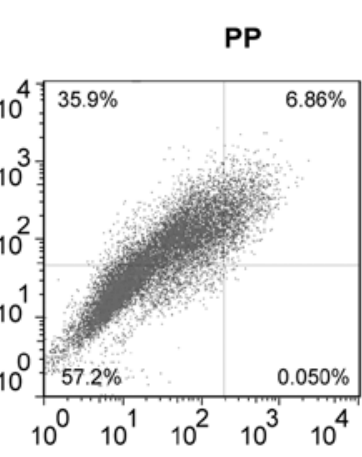

MDA-MB-231

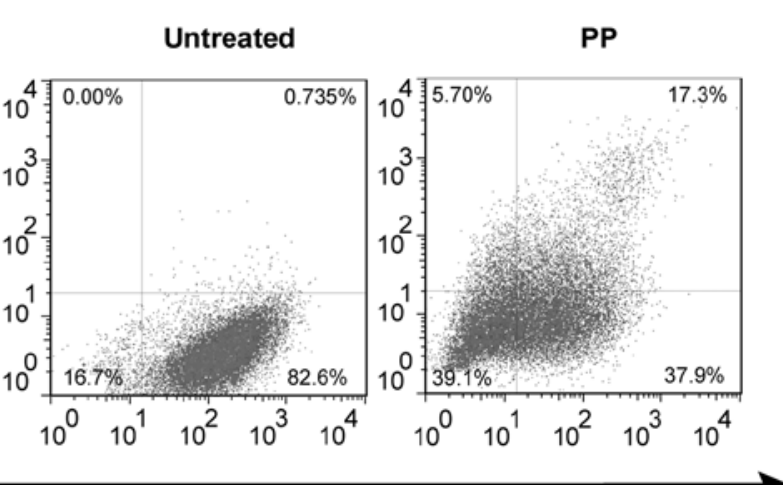

CD44

B

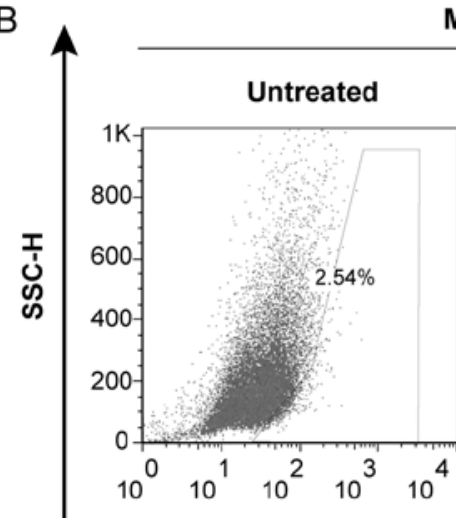

MCF-7

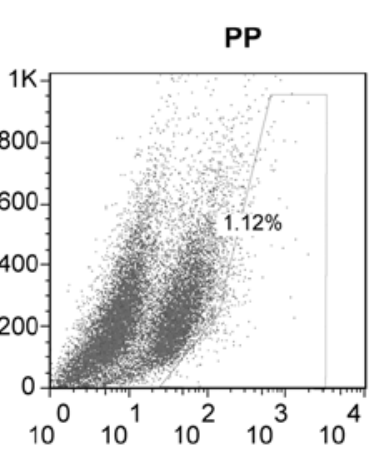

MDA-MB-231
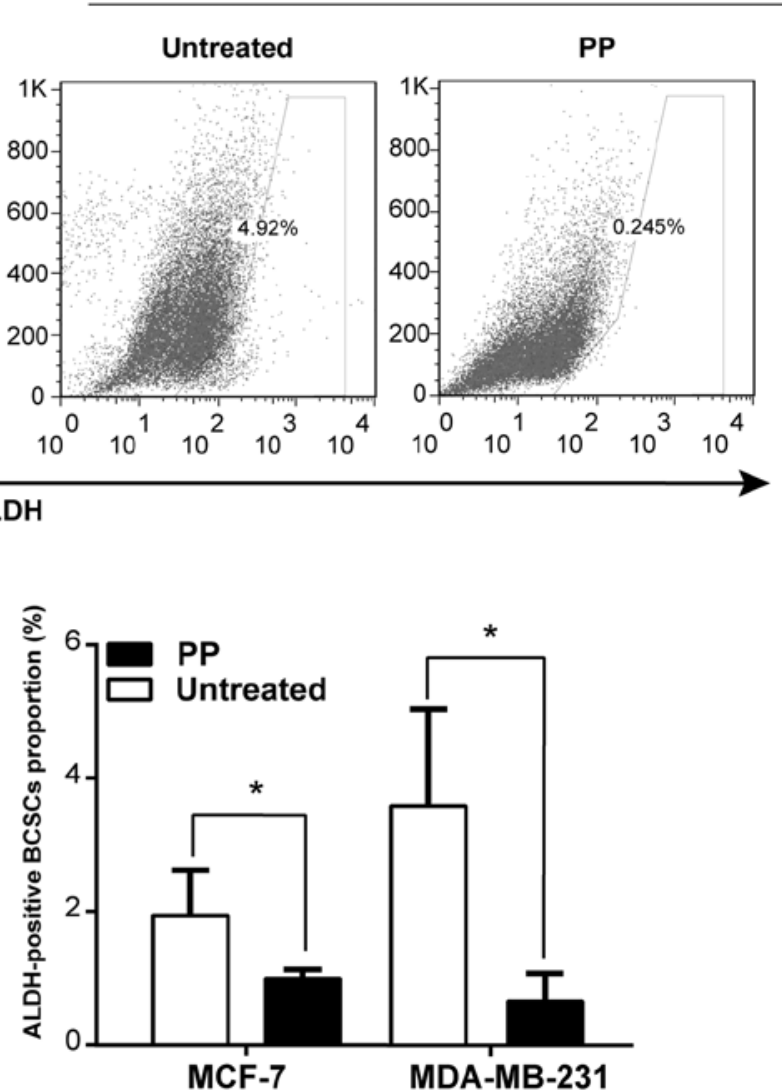

Figure 3. Effect of PP on the $\mathrm{CD} 44^{+} \mathrm{CD} 24 /$ low and ALDH-positive putative $\mathrm{BCSC}$ content in vitro. (A and C) Proportions of CD44 ${ }^{+} \mathrm{CD} 24 / \mathrm{low}$ putative BCSCs in PP-treated MCF-7 and MDA-MB-231 cells. (B and D) Proportion of ALDH-positive population in PP-treated MCF-7 and MDA-MB-231 cells. MCF-7 and MDA-MB-231 breast cancer cells were treated with PP for $72 \mathrm{~h}$ at a concentration of 200 and 1,000 nM, respectively. The CD44+CD24/low and ALDH-positive cells were measured by flow cytometry. Similar results were obtained in three independent experiments, and the representative flow cytometry plots are shown. ${ }^{*} \mathrm{P}<0.05$. PP, pyrvinium pamoate; BCSC, breast cancer stem cell; ALDH, aldehyde dehydrogenase.

regulated the expression of other stemness genes including ALDH1, CD44 and ABCG2 (Fig. 6B). To sum up, all these results pointed towards the possibility that $\mathrm{PP}$ inhibits $\mathrm{BCSC}$ activity through attenuating WNT pathway activity and downregulating stemness regulators.

\section{Discussion}

In the past decade, evidence has mounted for the role of the WNT signaling pathway during embryogenesis and physiolog- ical organogenesis (38). More recently, the WNT pathway also has been identified as an important regulator of self-renewal capacity in CSCs and a potential high-yield therapeutic target (20). Although no FDA-approved drugs that regulate WNT signaling are available to date (18), improved drug-screening platforms and new technologies have discovered agents that can alter WNT signaling in preclinical models $(39,40)$. However, because the WNT pathway is shared with normal stem cells, most of the compounds may be proved difficult not to damage normal stem cells and thereby limit their use (8). 

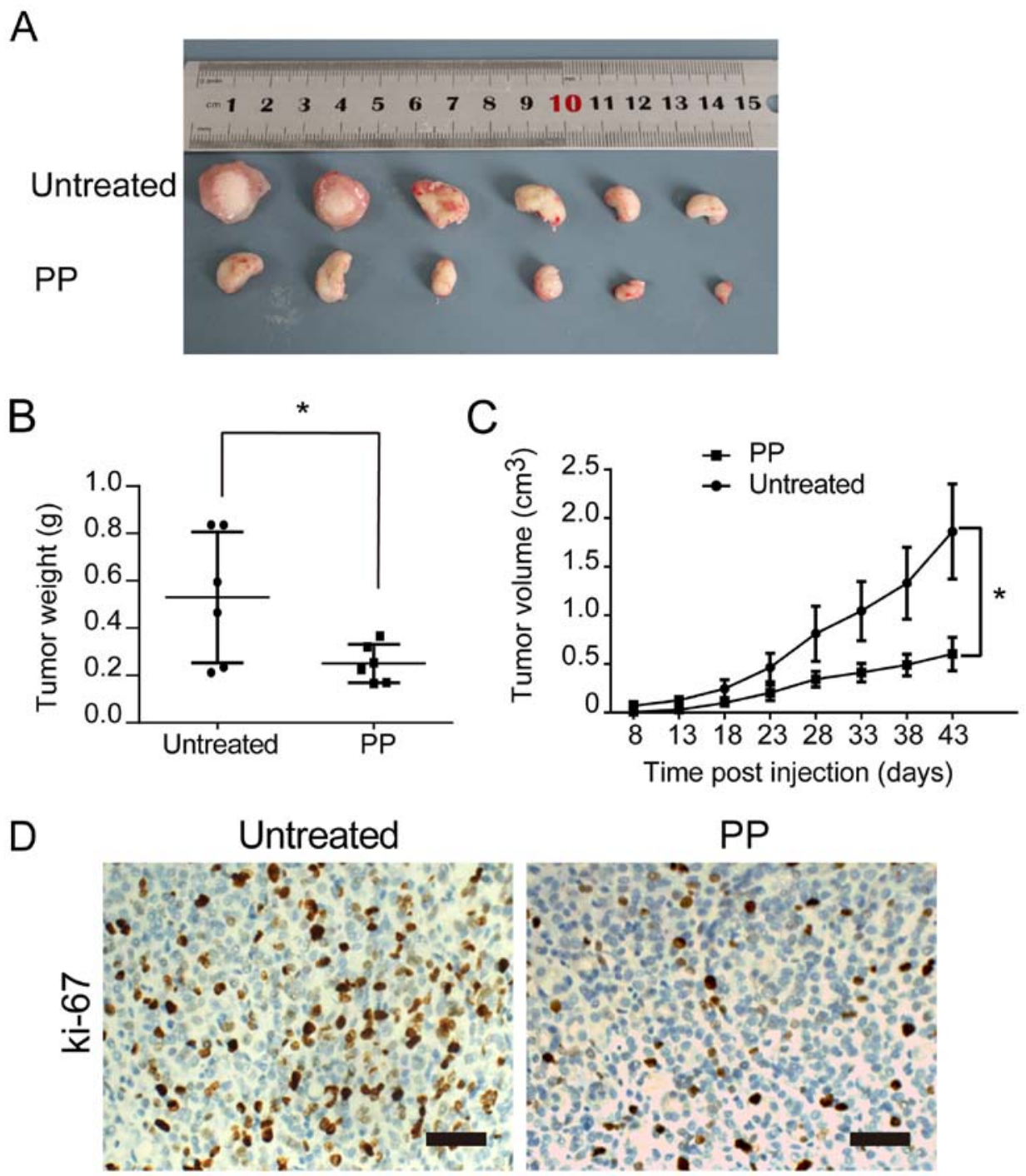

Figure 4. PP decreases tumorigenicity of BCSCs in vivo. (A) PP markedly reduced the tumor size in the xenograft model. A total of $5 \times 10^{6} \mathrm{PP}-$ pretreated (500 $\mathrm{nM}$ for $72 \mathrm{~h}$ ) MDA-MB-231 cells or untreated MDA-MB-231 cells were injected into the mammary fat pad of the NOD/SCID mice. (B) Final weight of harvested tumors of each group $(\mathrm{n}=6)$. (C) Tumor growth curves of the PP-pretreated group and the control group (n=6). (D) Representative images of immunohistochemical analysis of Ki-67 from harvested formalin-fixed tumors of each group. Data are reported as mean $\pm \mathrm{SD}(\mathrm{n}=6)$. ${ }^{*} \mathrm{P}<0.05$. $\mathrm{PP}$, pyrvinium pamoate; BCSC, breast cancer stem cell.

Hence, pyrvinium pamoate (PP), a classical anthelmintic drug, is attracting particular attention as a novel WNT pathway inhibitor. Recent studies have demonstrated that PP can exert a potent anticancer activity in several cancer types via inhibiting WNT pathway activity and autophagy process $(15,17,19,41)$, but reports describing the effect of PP on breast cancer cells, especially on BCSCs, are scarce.

The CSC hypothesis has been proposed for years. Theoretically, if BCSCs were totally eliminated, the remaining non-stem tumor cells would be unable to re-grow or to promote new tumors. Given that conventional agents fail to eliminate the BCSCs that evade therapy to drive patient relapse, new potential targets and drugs that kill both BCSCs and nontumorigenic cancer cells are now clinically warranted (42).

The present investigation examined the ability of PP to inhibit breast cancer cells proliferation. Our cell viability assays demonstrated that PP substantially suppressed proliferation of four genetically different breast cancer cell lines (Fig. 1A). Interestingly, the claudin-low breast cancer cell line MDA-MB-231 showed a relatively higher $\mathrm{IC}_{50}$, compared with all other cell lines (Fig. 1B). These results may be partly explained by two phenomena: the claudin-low subtype most closely resembles the epithelial stem cells $(43,44)$; and the $\mathrm{CD} 44^{+} / \mathrm{CD} 24^{-/ \text {low }} /$ claudin-low profile is increased in post-treatment samples after neoadjuvant chemotherapy or hormonal therapy (45). These findings together suggest different biological features (such as drug-resistance) associated with BCSCs converging in the claudin-low phenotype (43). PP has been described to function as a potent inhibitor of self-renewal via multiple mechanisms $(15,19,46)$. Hence, we further explored the effect of PP on BCSC self-renewal capacity. Similarly, we also validated that PP has the capacity to inhibit mammosphere formation and colony formation of BCSCs (Fig. 2B-E). Moreover, our xenograft model also confirmed that the effect of PP on tumorigenicity decreased although the result was limited to a single breast cancer cell line (MDAMB-231) (Fig. 4A and B). Indeed, MDA-MB-231 is one of the most aggressive breast cancer cell lines and has the highest 
A

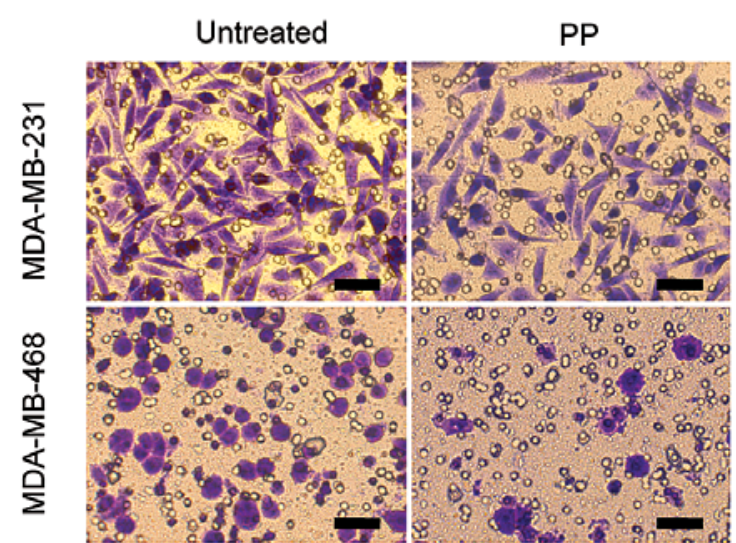

C

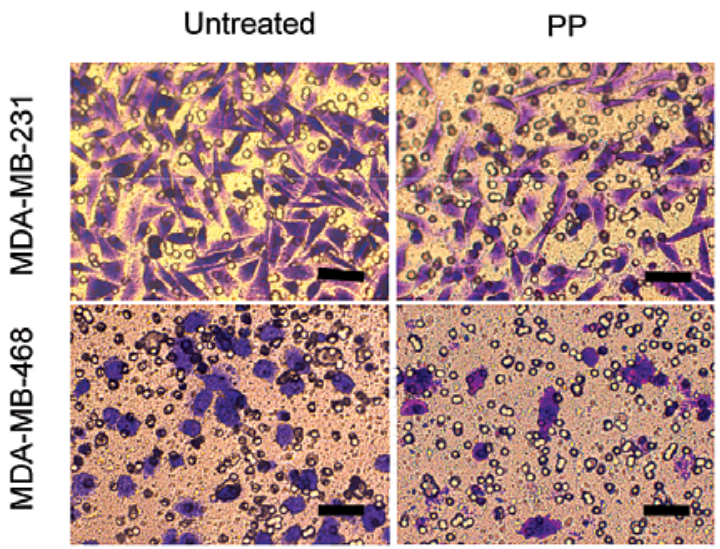

E

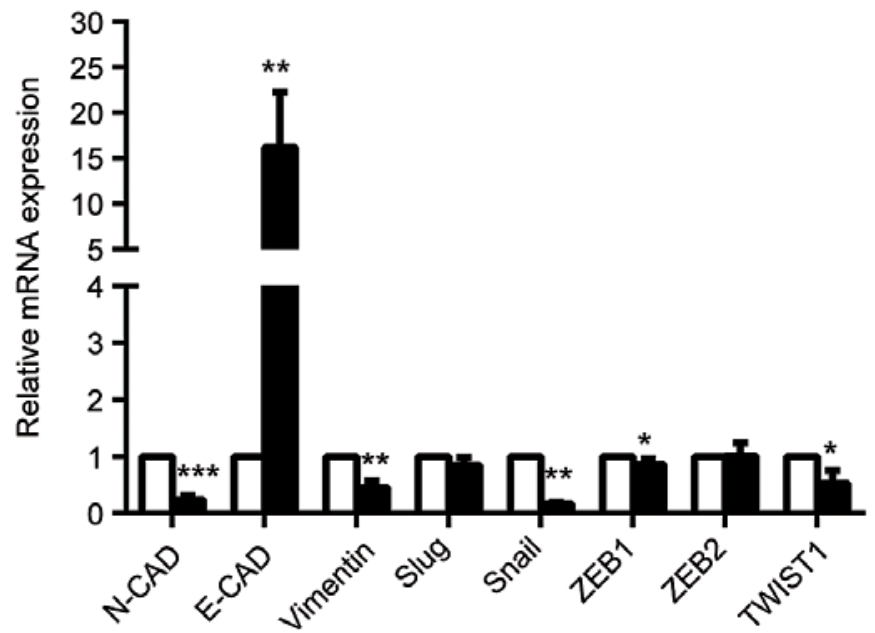

B

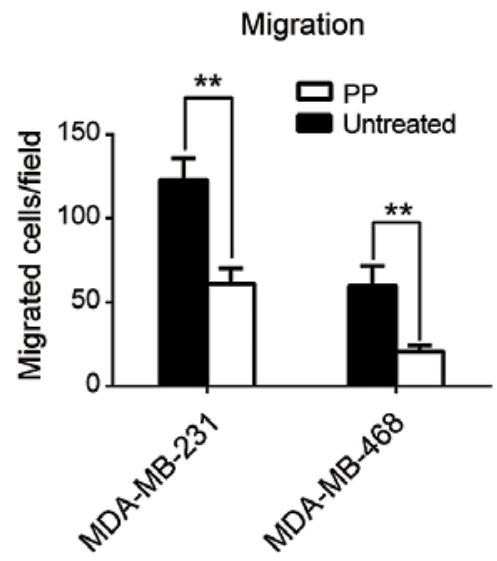

D

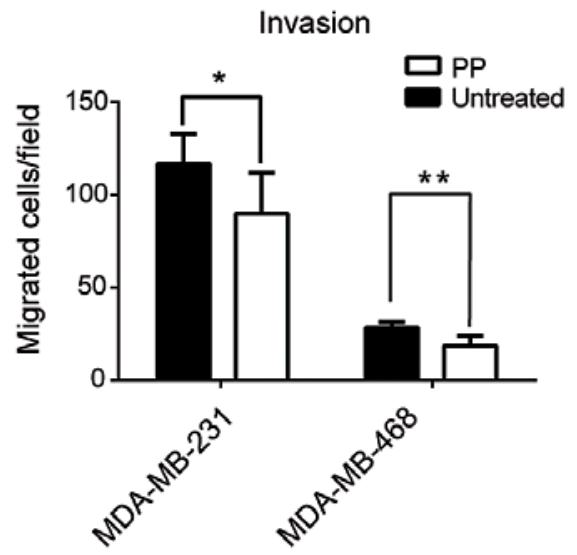

F

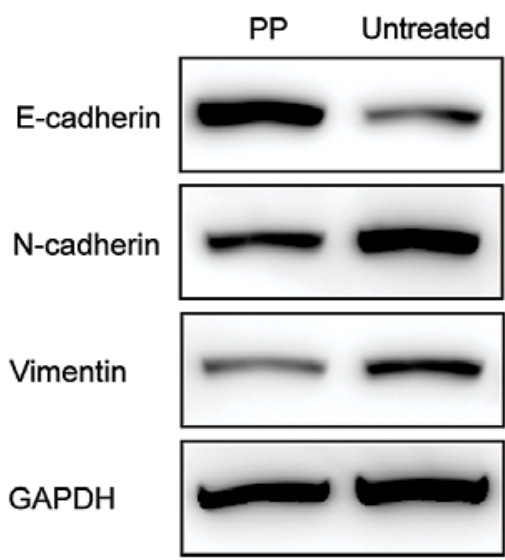

$135 \mathrm{kDa}$

$135 \mathrm{kDa}$

$57 \mathrm{kDa}$

$37 \mathrm{kDa}$

Figure 5. PP suppresses metastatic potential and EMT process in breast cancer. Transwell assay was used to evaluate the inhibitory effect of PP on migratory (A and C) and invasive potential (B and D) of MDA-MB-231 and MDA-MB-468 breast cancer cells. (E) Real-time PCR was used to analyse the gene expression of E-cadherin, N-cadherin, vimentin, Snail, Slug, ZEB1, ZEB2 and Twist1. (F) Western blot analysis of EMT-related markers. In Transwell assay, the concentration of PP used for MDA-MB-231 and MDA-MB-468 was 500 and $100 \mathrm{nM}$, respectively. The cell lysates for the immunoblot assay were obtained from the PP-treated MDA-MB-231 (1,000 nM, $72 \mathrm{~h})$ and control cells. Data are reported as mean $\pm \mathrm{SD},{ }^{*} \mathrm{P}<0.05,{ }^{* *} \mathrm{P}<0.01,{ }^{* * *} \mathrm{P}<0.001$. Scale bar, $50 \mu \mathrm{m}$. PP, pyrvinium pamoate; EMT, epithelial-mesenchymal transition.

$\mathrm{CD} 44^{+} \mathrm{CD} 24^{- \text {/low }} \mathrm{BCSC}$ frequency $(\sim 90 \%)$. Thus, our in vivo study result may be more broadly applicable including for less aggressive subtypes such as luminal breast cancer. Taken together, these findings clearly demonstrated the effectiveness of PP to overcome proliferation and self-renewal of both anchorage-dependent cells and BCSCs. At this juncture, it is 


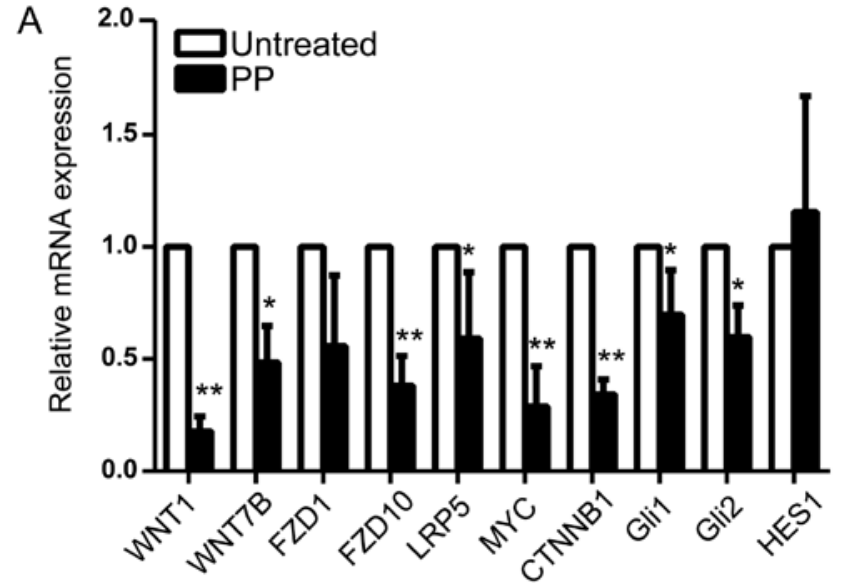

B

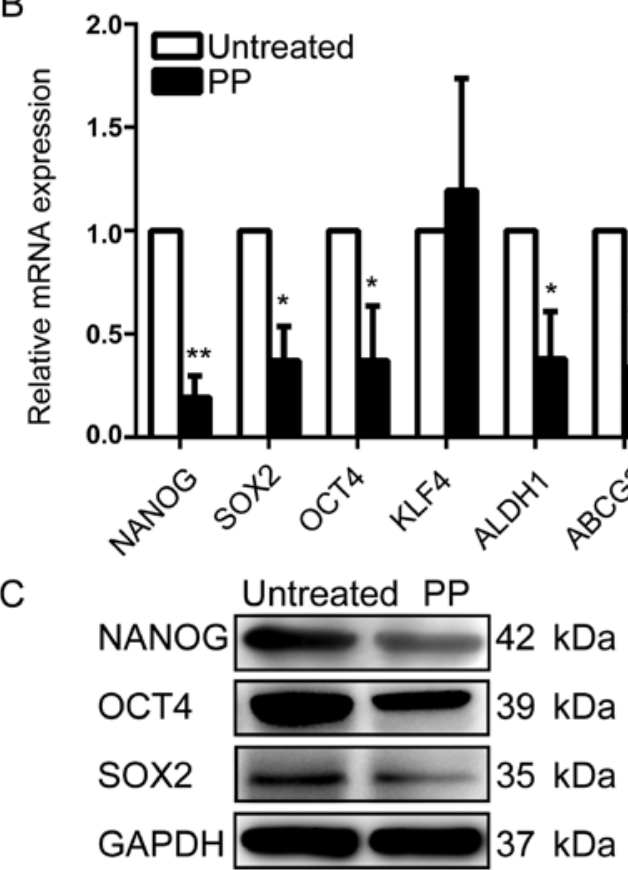

Figure 6. PP inhibits WNT pathway activity and stemness regulator expression. After $72 \mathrm{~h}$ PP treatment, real-time PCR was used to analyse (A) WNT, $\mathrm{Shh}$, and Notch pathway activity and (B) stemness regulator expression. (C) Western blot analysis of stemness genes. The total RNA for the realtime PCR and the cell lysates for the immunoblotting assay were from the PP-treated MDA-MB-231 cells $(1,000 \mathrm{nM}, 72 \mathrm{~h})$ and control. Data are reported as mean $\pm \mathrm{SD},{ }^{*} \mathrm{P}<0.05,{ }^{* *} \mathrm{P}<0.01$.

quite logical to postulate that PP might emerge as a promising drug for successful eradiation of breast cancer.

With continual refinement of massive parallel sequencing (MPS) technologies markedly shorten the path to fully personalized medicine, however, tumor heterogeneity will be one of the greatest challenges to manage in this endeavor (47). Notably, Venugopal et al revealed PP can selectively target TICs that drive tumor heterogeneity in human glioblastoma (15). In breast cancer, a previous study revealed that the overlap between CD $44^{+} \mathrm{CD} 24^{- \text {low }}$ and ALDH-positive CSC phenotypes seems to be very small $(<1 \%)$ (48). Additionally, it has been proven that their distributions among intrinsic breast cancer subtypes were different $(2,49)$. Basal-like tumors contained a higher percentage of CSCs with CD $44^{+} \mathrm{CD} 24^{- \text {low }}$ phenotype, whereas ALDH enzyme activity was mainly found in HER-OE and basal/epithelial breast cancer cells. The CD $44^{+} \mathrm{CD} 24^{-1}$ low and ALDH-positive subsets seem to identify CSCs with distinct levels of differentiation (2). Most importantly, previous studies reported variable therapeutic responses on different CSC populations $(24,27)$. Due to these discrepancies, we next analysed whether PP was able to reduce $\mathrm{CD}_{4} 4^{+} /$ $\mathrm{CD} 24^{-/ \text {low }}$ and ALDH-positive subpopulation which are the most two consistently used methods to identify and isolate BCSCs. Interestingly, we noted that both CD $44^{+} \mathrm{CD} 24^{-/ \text {low }}$ and ALDH-positive BCSCs population decreased after 3-day PP treatment (Fig. 3C and D). Thus, we provide direct evidence that PP is an inhibitor of BCSCs and a novel agent to overcome heterogeneity in both BCSCs and non-stem tumor bulk.

Unlike differentiated epithelial cells, when detaching from the extracellular matrix during the migratory process, CSCs can avoid apoptosis and survive in the blood stream. Then, as it travels all over the body, CSCs are able to select a suitable site distant from the primary tumor and thrive in its new environment (50). Thus, it is believed that CSCs are able to metastasize to distant organs where they serve as seeds of metastatic lesions (35). Of note, our results showed that PP significantly reduced metastatic capacity of two of the most aggressive breast cancer cell lines (MDA-MB-231, MDA-MB-468) (Fig. 5A-D). Consistent with the above findings, a prior study also observed that intraperitoneal injection of PP caused a trend toward decreased lung metastasis in mice (46). Moreover, EMT-related genes (N-cadherin, vimentin, Snail, Twist1) were also confirmed to be downregulated in the presence of PP (Fig. 5E and F). Indeed, one key link between CSCs and metastasis may be the EMT, the process by which epithelial cells shed their epithelial characteristics in order to become mesenchymal cells with enhanced motility and spindle cell shape (7). Therefore, although more studies are needed to provide more direct evidence for the conclusions, our results point towards the possibility that PP circumvents BCSC migratory and metastatic potential by suppressing the EMT process.

As a WNT pathway inhibitor, PP has two targets in the WNT signaling cascade (51). On the one hand, PP was able to inhibit WNT pathway by enhancing casein kinase $1 \alpha(\mathrm{CK}-1 \alpha)$ activity (52). One the other hand, PP was also reported to inhibit Pygopus (PYG), a co-transcription factor of $\beta$-catenin, and thereby interfere with target gene transcription (51). However, other researchers also revealed PP is not a 'bona fide' activator of CK-1 $\alpha$ but promotes downregulation of Akt/PKB and GSK3 activation, thus, regulates WNT signaling (53). To delineate the mechanisms underlying the inhibitory effect of PP on BCSCs, we focused on the critical pathways that regulate the self-renewal of CSCs (WNT, Shh, and Notch signaling pathways). Similarly, we also found PP successfully attenuated WNT pathway activity and stemness regulator expression in BCSCs (Fig. 6A and B). Interestingly, the inhibitory function of PP was also identified in the Shh pathway, but not the Notch pathway (Fig. 6A). In line with our data, Li et al also showed that PP was a potent Shh pathway inhibitor, which acts by reducing the stability of the Gli family of transcription factors (36). Actually, crosstalk between the WNT and Shh pathways has been evidenced in cancer $(54,55)$. On the basis of these findings, we speculate that PP targets the overlapping components of WNT pathway and Shh pathway, 
and it warrants further studies (such as microarray assay and rescue experiment) to identify the target genes associated with the inhibition of BCSCs by PP.

Our current findings have direct implications with regard to evaluation of PP as a potent inhibitor of both BCSCs and non-tumorigenic cancer cells. However, it will take time for this information to be translated into clinic. Major concerns mainly focus on the absorption, distribution and systemic toxicity of PP. However, it is noteworthy that PP has been used as a classical anthelmintic drug for more than fifty years and the doses $(0-1,000 \mathrm{nM})$ used in our study were relatively low and safe. Another challenge before us is that when taken orally, the absorption of PP from the gut is minimal (56). Thus, the development of pharmaceutical technology to improve the drug delivery is urgently needed. Because BCSCs are also highly associated with chemo-resistance behavior (57), PP combination therapy with current chemotherapeutic agents (such as anthracyclines and taxanes) should be evaluated in future studies both in vitro and in vivo.

\section{Acknowledgements}

This study was supported by the National Natural Science Foundation of China grant (no. 81172522).

\section{References}

1. Chiba T, Kita K, Zheng YW, Yokosuka O, Saisho H, Iwama A, Nakauchi $\mathrm{H}$ and Taniguchi $\mathrm{H}$ : Side population purified from hepatocellular carcinoma cells harbors cancer stem cell-like properties. Hepatology 44: 240-251, 2006.

2. Ricardo S, Vieira AF, Gerhard R, Leitão D, Pinto R, CameselleTeijeiro JF, Milanezi F, Schmitt F and Paredes J: Breast cancer stem cell markers CD44, CD24 and ALDH1: Expression distribution within intrinsic molecular subtype. J Clin Pathol 64: 937-946, 2011.

3. O'Brien CA, Kreso A and Jamieson CH: Cancer stem cells and self-renewal. Clin Cancer Res 16: 3113-3120, 2010.

4. Lou H and Dean M: Targeted therapy for cancer stem cells: The patched pathway and ABC transporters. Oncogene 26 : $1357-1360,2007$

5. Ishii $H$, Iwatsuki $M$, Ieta $K$, Ohta $D$, Haraguchi N, Mimori $K$ and Mori M: Cancer stem cells and chemoradiation resistance. Cancer Sci 99: 1871-1877, 2008.

6. Chuthapisith S, Eremin J, El-Sheemey M and Eremin O: Breast cancer chemoresistance: Emerging importance of cancer stem cells. Surg Oncol 19: 27-32, 2010.

7. Saadin K and White IM: Breast cancer stem cell enrichment and isolation by mammosphere culture and its potential diagnostic applications. Expert Rev Mol Diagn 13: 49-60, 2013.

8. Sehl ME, Sinsheimer JS, Zhou H and Lange KL: Differential destruction of stem cells: Implications for targeted cancer stem cell therapy. Cancer Res 69: 9481-9489, 2009.

9. Malhotra GK, Zhao X, Band H and Band V: Shared signaling pathways in normal and breast cancer stem cells. J Carcinog 10 38, 2011.

10. Harrison H, Farnie G, Howell SJ, Rock RE, Stylianou S, Brennan KR, Bundred NJ and Clarke RB: Regulation of breast cancer stem cell activity by signaling through the Notch4 receptor. Cancer Res 70: 709-718, 2010.

11. Farnie G and Clarke RB: Mammary stem cells and breast cancer - role of Notch signalling. Stem Cell Rev 3: 169-175, 2007.

12. Czerwinska P and Kaminska B: Regulation of breast cancer stem cell features. Contemp Oncol (Pozn) 19A: A7-A15, 2015.

13. Zhao C, Chen A, Jamieson CH, Fereshteh M, Abrahamsson A, Blum J, Kwon HY, Kim J, Chute JP, Rizzieri D, et al: Hedgehog signalling is essential for maintenance of cancer stem cells in myeloid leukaemia. Nature 458: 776-779, 2009.

14. Tomasetti C and Vogelstein B: Cancer etiology. Variation in cancer risk among tissues can be explained by the number of stem cell divisions. Science 347: 78-81, 2015.
15. Venugopal C, Hallett R, Vora P, Manoranjan B, Mahendram S, Qazi MA, McFarlane N, Subapanditha M, Nolte SM, Singh M, et al: Pyrvinium targets CD133 in human glioblastoma brain tumor-initiating cells. Clin Cancer Res 21: 5324-5337 2015.

16. Abetov D, Mustapova Z, Saliev T, Bulanin D, Batyrbekov K and Gilman CP: Novel small molecule inhibitors of cancer stem cell signaling pathways. Stem Cell Rev 11: 909-918, 2015.

17. Harada Y, Ishii I, Hatake K and Kasahara T: Pyrvinium pamoate inhibits proliferation of myeloma/erythroleukemia cells by suppressing mitochondrial respiratory complex I and STAT3. Cancer Lett 319: 83-88, 2012.

18. Wiegering A, Uthe FW, Hüttenrauch M, Mühling B, Linnebacher M, Krummenast F, Germer CT, Thalheimer A and Otto C: The impact of pyrvinium pamoate on colon cancer cell viability. Int J Colorectal Dis 29: 1189-1198, 2014.

19. Zhang X, Lou Y, Zheng X, Wang H, Sun J, Dong Q and Han B: Wnt blockers inhibit the proliferation of lung cancer stem cells. Drug Des Devel Ther 9: 2399-2407, 2015.

20. Reya $\mathrm{T}$ and Clevers $\mathrm{H}$ : Wnt signalling in stem cells and cancer. Nature 434: 843-850, 2005

21. Polyak K: Heterogeneity in breast cancer. J Clin Invest 121 : 3786-3788, 2011.

22. Sorlie T, Tibshirani R, Parker J, Hastie T, Marron JS, Nobel A, Deng S, Johnsen H, Pesich R, Geisler S, et al: Repeated observation of breast tumor subtypes in independent gene expression data sets. Proc Natl Acad Sci USA 100: 8418-8423, 2003.

23. Lorico A and Rappa G: Phenotypic heterogeneity of breast cancer stem cells. J Oncol 2011: 135039, 2011.

24. Wang A, Chen L, Li C and Zhu Y: Heterogeneity in cancer stem cells. Cancer Lett 357: 63-68, 2015.

25. Chen J, Li Y, Yu TS, McKay RM, Burns DK, Kernie SG and Parada LF: A restricted cell population propagates glioblastoma growth after chemotherapy. Nature 488: 522-526, 2012.

26. Bao S, Wu Q, McLendon RE, Hao Y, Shi Q, Hjelmeland AB, Dewhirst MW, Bigner DD and Rich JN: Glioma stem cells promote radioresistance by preferential activation of the DNA damage response. Nature 444: 756-760, 2006.

27. Liu Y, Nenutil R, Appleyard MV, Murray K, Boylan M, Thompson AM and Coates PJ: Lack of correlation of stem cell markers in breast cancer stem cells. Br J Cancer 110: 2063-2071, 2014.

28. Bozkulak EC and Weinmaster G: Selective use of ADAM10 and ADAM17 in activation of Notch1 signaling. Mol Cell Biol 29: 5679-5695, 2009

29. Appleyard MV, Murray KE, Coates PJ, Wullschleger S, Bray SE, Kernohan NM, Fleming S, Alessi DR and Thompson AM: Phenformin as prophylaxis and therapy in breast cancer xenografts. Br J Cancer 106: 1117-1122, 2012.

30. Livak KJ and Schmittgen TD: Analysis of relative gene expression data using real-time quantitative PCR and the 2(-Delta Delta C(T)) method. Methods 25: 402-408, 2001.

31. Reynolds BA and Weiss S: Generation of neurons and astrocytes from isolated cells of the adult mammalian central nervous system. Science 255: 1707-1710, 1992.

32. Lu S and Labhasetwar V: Drug resistant breast cancer cell line displays cancer stem cell phenotype and responds sensitively to epigenetic drug SAHA. Drug Deliv Transl Res 3: 183-194, 2013.

33. Lombardo Y, de Giorgio A, Coombes CR, Stebbing J and Castellano L: Mammosphere formation assay from human breast cancer tissues and cell lines. J Vis Exp: Mar 22, 2015 (Epub ahead of print). doi: 10.3791/52671.

34. Hwang-Verslues WW, Lee WH and Lee EY: Biomarkers to target heterogeneous breast cancer stem cells. J Mol Biomark Diagn (Suppl 8): 6, 2012.

35. Luo M, Brooks M and Wicha MS: Epithelial-mesenchymal plasticity of breast cancer stem cells: Implications for metastasis and therapeutic resistance. Curr Pharm Des 21: 1301-1310, 2015.

36. Li B, Fei DL, Flaveny CA, Dahmane N, Baubet V, Wang Z, Bai F, Pei XH, Rodriguez-Blanco J, Hang B, et al: Pyrvinium attenuates Hedgehog signaling downstream of smoothened. Cancer Res 74: 4811-4821, 2014

37. Bourguignon LY, Wong G, Earle C and Chen L: HyaluronanCD44v3 interaction with Oct4-Sox2-Nanog promotes miR-302 expression leading to self-renewal, clonal formation, and cisplatin resistance in cancer stem cells from head and neck squamous cell carcinoma. J Biol Chem 287: 32800-32824, 2012.

38. Peifer $M$ and Polakis P: Wnt signaling in oncogenesis and embryogenesis - a look outside the nucleus. Science 287: $1606-1609,2000$ 
39. Anastas JN and Moon RT: WNT signalling pathways as therapeutic targets in cancer. Nat Rev Cancer 13: 11-26, 2013.

40. Dihlmann S and von Knebel Doeberitz M: Wnt/beta-cateninpathway as a molecular target for future anti-cancer therapeutics. Int J Cancer 113: 515-524, 2005.

41. Deng L, Lei Y, Liu R, Li J, Yuan K, Li Y, Chen Y, Liu Y, Lu Y, Edwards CK III, et al: Pyrvinium targets autophagy addiction to promote cancer cell death. Cell Death Dis 4: e614, 2013.

42. Gangopadhyay S, Nandy A, Hor P and Mukhopadhyay A: Breast cancer stem cells: A novel therapeutic target. Clin Breast Cancer 13: 7-15, 2013.

43. Prat A, Parker JS, Karginova O, Fan C, Livasy C, Herschkowitz JI, $\mathrm{He} \mathrm{X}$ and Perou CM: Phenotypic and molecular characterization of the claudin-low intrinsic subtype of breast cancer. Breast Cancer Res 12: R68, 2010.

44. Asiedu MK, Ingle JN, Behrens MD, Radisky DC and Knutson KL: TGFbeta/TNF(alpha)-mediated epithelial-mesenchymal transition generates breast cancer stem cells with a claudin-low phenotype. Cancer Res 71: 4707-4719, 2011.

45. Creighton CJ, Li X, Landis M, Dixon JM, Neumeister VM, Sjolund A, Rimm DL, Wong H, Rodriguez A, Herschkowitz JI, et al: Residual breast cancers after conventional therapy display mesenchymal as well as tumor-initiating features. Proc Natl Acad Sci USA 106: 13820-13825, 2009.

46. Xu W, Lacerda L, Debeb BG, Atkinson RL, Solley TN, Li L, Orton D, McMurray JS, Hang BI, Lee E, et al: The antihelmintic drug pyrvinium pamoate targets aggressive breast cancer. PLoS One 8: e71508, 2013.

47. Swanton C, Burrell RA and Futreal PA: Breast cancer genome heterogeneity: A challenge to personalised medicine? Breast Cancer Res 13: 104, 2011.

48. Ginestier C, Hur MH, Charafe-Jauffret E, Monville F, Dutcher J, Brown M, Jacquemier J, Viens P, Kleer CG, Liu S, et al: ALDH1 is a marker of normal and malignant human mammary stem cells and a predictor of poor clinical outcome. Cell Stem Cell 1: 555-567, 2007.
49. de Beça FF, Caetano P, Gerhard R, Alvarenga CA, Gomes M, Paredes J and Schmitt F: Cancer stem cells markers CD44, CD24 and ALDH1 in breast cancer special histological types. J Clin Pathol 66: 187-191, 2013.

50. Bill R and Christofori G: The relevance of EMT in breast cancer metastasis: Correlation or causality? FEBS Lett 589: 1577-1587, 2015.

51. Thorne CA, Hanson AJ, Schneider J, Tahinci E, Orton D, Cselenyi CS, Jernigan KK, Meyers KC, Hang BI, Waterson AG, et al: Small-molecule inhibition of Wnt signaling through activation of casein kinase $1 \alpha$. Nat Chem Biol 6: 829-836, 2010.

52. Saraswati S, Alfaro MP, Thorne CA, Atkinson J, Lee E and Young PP: Pyrvinium, a potent small molecule Wnt inhibitor, promotes wound repair and post-MI cardiac remodeling. PLoS One 5: e15521, 2010.

53. Venerando A, Girardi C, Ruzzene M and Pinna LA: Pyrvinium pamoate does not activate protein kinase CK1, but promotes Akt/PKB down-regulation and GSK3 activation. Biochem J 452: 131-137, 2013.

54. Song L, Li ZY, Liu WP and Zhao MR: Crosstalk between Wnt $/ \beta$-catenin and Hedgehog/Gli signaling pathways in colon cancer and implications for therapy. Cancer Biol Ther 16: 1-7, 2015.

55. Yanai K, Nakamura M, Akiyoshi T, Nagai S, Wada J, Koga K, Noshiro H, Nagai E, Tsuneyoshi M, Tanaka M, et al: Crosstalk of hedgehog and Wnt pathways in gastric cancer. Cancer Lett 263: 145-156, 2008

56. Smith TC, Kinkel AW, Gryczko CM and Goulet JR: Absorption of pyrvinium pamoate. Clin Pharmacol Ther 19: 802-806, 1976.

57. Bartucci M, Dattilo R, Moriconi C, Pagliuca A, Mottolese M, Federici G, Benedetto AD, Todaro M, Stassi G, Sperati F, et al: TAZ is required for metastatic activity and chemoresistance of breast cancer stem cells. Oncogene 34: 681-690, 2015. 